\title{
FACTORS OF IMPORTANCE FOR DETERMINING DAYTIME VERSUS NIGHTIME OPERATIONS IN OREGON
}

\author{
Sang-Bin Park and Kimberly D. Douglas, P.E.* \\ College of Engineering \\ Oregon State University \\ 118 Covell Hall \\ Corvallis, OR 97331, USA \\ Phone: 541-737-2365 \\ FAX: 541-737-5241
}

E-mails: parksa@engr.orst.edu and kimberly.d.douglas@ orst.edu

Andrew S. Griffith, P.E., and Kevin J. Haas, P.E. Research Group Oregon Department of Transportation 200 Hawthorne SE, Suite B-240

Salem, OR 97301-5192, USA

Phone: 503-986-2848

FAX: 503-986-2844

E-mail: kevin.j.haas@odot.state.or.us

Word Count: 7420

Submission Date: July 31, 2001

*Corresponding Author: Kimberly D. Douglas 


\begin{abstract}
The State of Oregon is in the process of developing a decision model which will be used to improve the decisionmaking process concerning daytime versus nighttime construction and maintenance activities. In reviewing the literature, a comprehensive list of factors was available which was well defined and articulated. However, the literature did not provide information on the relative importance of the various factors. This paper provides the findings from the literature review, and results from an extensive survey. The survey details the views of 446 respondents from within the state of Oregon and 25 other states. Congestion, traffic control, and safety were the most important factors in making these decisions.
\end{abstract}

\title{
BACKGROUND
}

As the Oregon Department of Transportation (ODOT) has placed more emphasis on preservation of existing highways and bridges, daytime lane closures accommodating maintenance and construction activities are becoming a serious problem. Lane closures on highways already near capacity will add to congestion. Also, seasonal traffic conditions are a consideration in rural areas where lane closures impact levels of service on highways to and from popular recreational areas. To counter the disruption of daytime traffic flow, more maintenance and construction activities are being accomplished at night. Nighttime maintenance and construction eliminates daytime disruption of traffic, but this also brings a new set of factors and concerns. Cost, productivity, quality, noise, human factors, safety, public awareness, and lighting are some of the concerns associated with nighttime operations. In deference to public concerns, ODOT has used, and continues to use, nighttime operations for maintenance and construction on many of its high volume highways. However, decision making for using nighttime operations is currently subjective and relies on judgment without the benefit of analytical data and evaluation criteria. This presents a serious challenge for ODOT project delivery managers who must make critical decisions on how the project is to be carried out despite minimal guidelines and objective criteria to assist them. Flawed assessments about when to conduct maintenance and construction operations can certainly lead to greater costs for ODOT and the highway user as well as elevated traffic and worker safety risks. It is therefore critical that the factors of importance to these decisions be identified and prioritized for inclusion in a decision making model.

\section{LITERATURE REVIEW}

The first step toward identifying and prioritizing the factors related to decision making about daytime versus nighttime activities was a thorough literature review on this topic. A comprehensive literature search located articles on the purpose of nighttime work, the advantages and disadvantages of nighttime work, accident studies, factors (parameters) affecting nighttime work, comparison of daytime versus nighttime work (decision making system), guidelines for nighttime work, and estimation and analysis of capacity/delay, cost, and productivity/quality. The literature summary most relevant to this discussion is included below.

\section{Factors (Parameters) Affecting to Nighttime Work}

In order to decide when to use nighttime work, factors (parameters) affecting nighttime work must be identified and weighted. Several studies preliminarily identified the factors $(1,2)$, and generally, these studies briefly addressed the factors without supportive data and explanations.

Hinze and Carlisle $(3,4)$ identified factors related to the decisions to conduct nighttime construction after studying state highway agencies' surveys. In order to collect data, a two-part survey questionnaire was designed. Part I was for construction engineers and transportation planners and Part II was for the project/resident engineers associated with nighttime projects. Considerations for nighttime roadwork fell into two categories: decision-making concerns and performance concerns. Decision-making concerns are typically addressed before the project takes place and performance concerns address planning the project both before and during the nighttime work.

In the survey of construction engineers and transportation planners, data was collected from 21 different state highway agencies (including Oregon) using a mail survey. Projects were investigated over a two-year span between 1987 and 1988, and a five-year span from 1984 to 1988. After statistical analysis, this study concluded that there was no significant difference between the cumulative response from all survey respondents and the responses of the individual states. This study found that many agencies have recently shifting towards awarding contracts to contractors who are conducting nighttime work. The importance of each factor rated from 1 to 7 by each respondent. The most important factor was rated as 7 , while the least important was rated as 1 . Congestion and safety were rated as the most important factors for the decision makers.

In Hinze and Carlisle (3) survey of project/resident engineers, telephone surveys were used to collect data from eighteen contractors in eleven states (not including Oregon). The average range of conducting nighttime work was $50 \%$. While a few contractors responded that nighttime work was safer due to less traffic, the majority of 
contractors indicated that it was very dangerous. Regarding the worker morale issue, more than $75 \%$ of the contractors did not have any problems. The overall average contract cost for nighttime work was about $10 \%$ higher.

In conclusion, this study indicated that the cost of a project to the owner was likely to be less important in making a decision to conduct nighttime work as compared to the cost impacts on the users (drivers and passengers) resulting from congestion. In addition, safety and noise were other important factors affecting the decision.

The studies by Ellis, Herbsman, Kumar \& Chheda (5) and Ellis, Herbsman, Chedda \& Epstein (6) took a different approach to identify and weight the factors. The following factors were identified, and these factors are categorized by their characteristics:

1) Construction-related factors: cost, quality, productivity, and noise

2) Traffic related factors: congestion, safety, and traffic control

3) Human factors: sleep, circadian rhythms, and social/domestic issues

4) Miscellaneous factors: public relations and information, supervision and communication, and supply and repair

A literature review and interviews with personnel who had experience in night operations in the United States allowed the identification of the above factors. After determining the factors, each factor's importance and effect on nighttime work was evaluated. In addition, projects around Florida were studied to determine how nighttime work was operated, and then guidelines for nighttime operation were developed.

After evaluating the factors, this study concluded that cost, quality, and productivity were not significantly different between daytime and nighttime operations. The quality of nighttime work was mostly related to lighting, so with sufficient lighting, projects produced similar quality to daytime work. Hypothesis testing did not indicate significant differences in productivity levels between daytime and nighttime work. However, congestion was a primary factor when deciding on nighttime operation and safety was a secondary factor due to the severity of accidents, even though accident rates were low. The final conclusion was that daytime and nighttime operations were not significantly different, especially with respect to cost. However, this study advised that evaluations and results would be different for different projects.

In 1993, Ellis et al. (7) identified factors influencing task illumination requirements for nighttime work. These factors included:

1) Human factors: age, visual acuity, response characteristics, and experience and familiarity

2) Environmental factors: weather conditions, fog/dust/smoke, wet/dry surfaces, and ambient glare and brightness

3) Lighting factors: geometric relationships, orientation, power of lamps, gradient uniformity, and glare

5) Task-related factors:

a. equipment attributes - speed, physical characteristics, response time

b. task physical attributes - type of target, size of target, appearance \& reflectance, location, seeing distance

c. task qualitative attributes - importance of task, accuracy required, visual difficulty, visual fatigue

d. background factors - reflectivity of surface, surface brightness

e. operation attributes - type of facility, facility environment, traffic control, location on highway

Among these factors, speed, accuracy, importance, reflectance, seeing distance, and the size of objects were significant factors related to lighting.

With the formerly discussed studies, Elrahman and Perry $(8,9)$ established a comprehensive set of factors (parameters) related to night operations. They used statistical data and findings from former studies in order to identify these factors. Their factors were:

1) Traffic-related parameters: congestion, safety, and traffic control

2) Construction-related parameters: productivity and quality

3) Social parameters: driver conditions and working conditions

4) Economic parameters: user costs, accident costs, maintenance costs, and construction costs

5) Environmental parameters: noise, fuel consumption, and air quality

6) Other parameters: scheduling, public relations, communication, supervision, availability of material/equipment repair, and lighting

The above study by Ellis et al. (10) was a detailed study to identify factors related only to the lighting issue during nighttime work, while the study by Elrahman and Perry $(8,9)$ was a broader study where the lighting factor was a single factor in another parameter category. These studies were intended to identify all possible factors that should be considered in making a decision. These factors should be weighted after investigating their importance for overall nighttime work. In addition, the study by Hinze and Carlisle $(3,4)$ investigated each factors' importance, but the number of investigated factors was not sufficient to cover all factors for nighttime work and the differential 
of the ranked values for the factors was too narrow. A method to weight the importance of each factor will be developed for the ODOT project.

\section{Conclusion from Literature Review}

Elrahman and Perry $(8,9)$ established a comprehensive set of factors (parameters) related to night operations. Their factors were:

1) Traffic-related parameters: congestion, safety, and traffic control

2) Construction-related parameters: productivity and quality

3) Social parameters: driver conditions and working conditions

4) Economic parameters: user costs, accident costs, maintenance costs, and construction costs

5) Environmental parameters: noise, fuel consumption, and air quality

6) Other parameters: scheduling, public relations, communication, supervision, availability of material/equipment repair, and lighting

After literature review, it was concluded that the above 19 factors were established well and were sufficient to utilize for the ODOT decision model. Thus, all 19 factors were used to create the survey. However, what was not available in the literature was any information on the relative importance of these factors in making decisions concerning daytime versus nighttime work. Thus, the decision was made to administer a survey to gain this information.

\section{SIGNIFICANCE OF STUDY}

The existing literature was used to identify the factors. The primary contribution of this paper is the establishment of factor rankings that can be used as weights in a decision model. This paper presents findings on the rankings and a future paper will detail the decision model currently being developed. The value to practitioners and other states is three fold. First, the response rate from other DOT's outside Oregon was very high ( 25 states responded) and these rankings could be used directly by other states in developing a model. Second, the process used in Oregon could be replicated in other states to further tailor a decision model to meet the specific state's needs. Third, if a state considers itself to be similar to Oregon, Oregon's results could be used directly. Further, Region 1 in Oregon is a metropolitan area, and the other regions include moderately populated areas and rural areas. The survey results found no significant differences between regions. Therefore, Oregon's results could be generalized to a variety of state applications.

\section{SURVEY TO DETERMINE FACTOR IMPORTANCE}

A thorough literature review revealed a list of factors considered to be relevant in decision making on daytime versus nighttime construction and maintenance work. In order to confirm the importance of these factors and clarify differences in importance between factors a comprehensive survey was made of state personnel that have experience in construction and maintenance operations in the Oregon Department of Transportation (ODOT). Surveys were administered to both employees of the state and contractors. In addition, department of transportation personnel from other states were surveyed in order to examine other states' current practices for comparative purposes.

After collecting the survey data, the responses were analyzed by personnel category (construction vs. maintenance), positions, and geographical location to investigate whether there were any significant differences between categories, positions, or geographies.

\section{Identifying Survey Personnel}

In order to determine which personnel should be surveyed, general operations in ODOT were investigated. Construction operations are mainly new road constructions including highways, rehabilitation of roads, and paving roads. The Project Managers (PM) are the chiefs in charge of the construction operations and their staff consists of an Assistant Project Manager (APM), Coordinators, Inspectors, and other positions. Generally, one inspector monitors each construction project and they supervise the project so that the procedures are conducted according to the project plan and they ensure that the quality of work is acceptable. Workers used for these construction projects are typically from local contractors. The workers from these local contractors are generally seasonal workers since ODOT does not usually do construction projects during the rainy seasons, except for long term-projects.

Maintenance personnel work on a very wide range of projects such as repairing roads and bridges, short length paving, road cleaning due to snow, repairing electronic and mechanical systems in dams, mowing shoulders, sign replacement, guardrail repair, and pavement patching. The District Managers (DM) are the supervisors of maintenance operations and their staff consists of an Assistant District Manager (ADM), Transportation Maintenance Managers (TMM) or Area Maintenance Managers (AMM), Coordinators, and other positions. Each 
district office is divided according to the county and a TMM or AMM monitors each smaller location. Generally, each location has permanent workers and facilities for maintenance projects.

Thus, it was necessary to survey all staff of PMs, DMs as well as contractors. In addition, the project's Technical Advisory Committee (TAC) recommended that other personnel involved in construction or maintenance projects such as Traffic Control Plans Designers (TCPDs) and Technical Services Resource Managers (TSRMs) needed to be surveyed. The Traffic Control Plan Unit is a statewide team, and they are located at the Salem headquarters. TCPDs produce a working set of contract plans for the Traffic Control portion of the project. In order to establish a plan, TCPDs collect a wide array of information regarding the geometry of the work site, traffic volumes, details for bridges, the type of work being done, and construction techniques. In addition, they are responsible for compiling a cost estimate for the Traffic Control Devices used in the Traffic Control Project.

TSRMs are located in each of the five regions in Oregon. They ensure that construction projects are successfully delivered by coordinating cooperation among the regions. On time, on budget, right scope, quality, and customers' needs are the main elements to monitor in each project. Also, they are responsible for statewide technical discipline of roadway engineering such as consistency, efficiency, and product quality (legal and sound engineering, biddable and constructible projects), developing an engineering force for the future, and meeting Oregon State Board of Examiners for Engineering and Land Surveyors (OSBEELS) requirements.

Finally, this project surveyed personnel outside of Oregon to compare Oregon's priorities with that of the other states. Thus, representative decision makers from the other states were invited to respond to an electronic version of the survey. Therefore, this study ultimately surveyed five different types of personnel. Figure 1 shows a graphic representation of the categories of personnel surveyed.

\section{Developing and Conducting the Survey}

The purpose of the survey was to confirm if the factors identified from the literature were important within the state of Oregon, and if so, what was their importance relative to the other factors. This information would be incorporated into a decision model to assist in making determinations of whether daytime or nighttime construction and maintenance work should be done. The survey was developed based upon the identified 19 factors from the literature. It consisted of two parts, which will be referred to as "indicating" and "ranking" factors. The reason for including both formats in the survey was to determine relative importance between factors and to check for consistencies between the two response methods. Open-ended questions were included at the end to acquire additional information. For the indicating factors, participants were asked to rate each factor from 1 to 7 where 1 is the lowest and 7 the highest level of importance. For ranking factors, the survey asked respondents to rank all 19 factors from 1 to 19, with 1 being the most important factor and 19 being the least important factor. Through indicating and ranking factors, this study enabled us to investigate whether each factor has consistent importance between the indicating and ranking methods. In addition, preferences between daytime and nighttime work were requested along with the reasoning for the preference. Finally, respondents were asked if there was any other information they would like to share.

After developing the survey, the investigators decided to visit all of the PM and DM offices across the state, as well as, TCPD and TSRM regular meetings to increase response rates since other approaches (e.g., mail, telephone, web-based) have traditionally shown lower response rates, usually lower than $30 \%$. Investigators visited each office during its regular meeting with its staff and surveyed them after providing a brief explanation about the ODOT project and the survey. Thus, the response rate for this survey was exceptional at over $90 \%$. In order to not create bias between participants, investigators did not answer any questions from participants during the survey completion.

In order to survey contractors, investigators attended an annual meeting of the Association of General Contractors (AGC) and met with both contractors and ODOT personnel. Surveys were distributed to the contractors who attended this meeting, and in addition, AGC faxed a copy of the survey to all of its members. The faxed distribution allowed the contractors to fax back their response, and this significantly increased the response rate. In order to classify the responses from the contractors a question about their experience with nighttime work and a question about the type of work they do (e.g., bridges, paving, excavation) were added to the survey.

In order to survey other state departments of transportation (DOTs), a web-designed survey was used. The survey added two questions to the base survey: 1) experience with nighttime work in their state and 2) the decision process they use to determine when to conduct nighttime work.

\section{Results}

In order to effectively understand the results of this survey, the results must be considered from various perspectives. First, overall results which combine PMs, DMs, Contractors, TSRMs, TCPDs, and other DOTs are shown. The 
categories of responses will then be discussed. Finally, comparative analyses between overall results and each individual category will be presented. In addition, PM and DM results are analyzed by regions and positions to investigate any differences that might arise among regions or positions. The preference of work time and other information will be addressed last.

\section{Respondent Demographics}

Figures 2 shows the demographics of the survey responses. In total, 446 survey responses were obtained. Table 1 details which states responded to the survey and if a state provided multiple responses. The response rate was $50 \%$ from states across the nation.

\section{Overall Results}

Table 2 provides the results from all respondents considered as a single group. The factors are sorted by ascending order of the "indicating" value. The table is divided into four sections with bold lines. These lines represent locations where the factors could be divided such that the factors in each section appear in both the indicating and ranking factors. In other words, for both the indicating and ranking factors, safety, traffic control, and congestion were the most important factors affecting nighttime work. These are in the top section of the Table 2. Similarly, air quality and fuel consumption rated as the least important for both categories. These are in bottom section of the Table 2. The five factors in these two sections are shaded with dark and light gray colors respectively in Table 3-6 to visually illustrate their relative importance to the different groups.

The second and third sections enumerate the factors of secondary and tertiary importance, respectively. The method for separating the sections is the presence of each factor in the section. For example, even though lighting factor was differently ranked in the indicating and ranking cases, the factor can be found in the second section in the both cases.

The factors in the upper section were consistent across all groupings (PMs, DMs, TSRMs, TCPDs, and other DOTs), except for the Contractors. The least important factors were likewise consistent across all groups, including the contractor responses.

In order to decide whether the overall results can be used as a direct representation of the population, results by each personnel category should be individually examined. Then it is necessary to compare among them to know whether there are any significant differences between any categories.

\section{PMs' Results}

Table 3 illustrates the survey results from PM personnel. The data between the highest and lowest factors' sections are divided into three sections by bold lines. The first section contains the six factors that can be expected to be the second most important set of factors in nighttime work. From their experience, many inspectors, as well as other personnel, found these issues to be of concern during nighttime work. Comments indicated that many inspectors experienced accidents due to drunken drivers. From this analysis, one could conclude that the four types of cost factors (accident, construction, uses, and maintenance) are less important than the other factors to this PM personnel. It is necessary to examine those cost factors further in other response groups.

PM results appear to be consistent with the perspective one would expect. For example, since contractors rather than PMs are impacted by construction issues such as availability of material, equipment repair, and communication supervision, PMs considered these factors to be of lesser importance. Also, the maintenance cost factor is low because this issue is not within their domain. Rather, it is the responsibility of the DM operation.

DMs' Results

Table 4 shows the results for the surveys from DM personnel. There are two sections between the highest and the lowest sections. The factors of communication supervision, user cost, and noise were rated relatively lower in importance. Since the project length of DMs' operations is relatively short, communication supervision and noise are consequently lower in priority. Some maintenance projects can be conducted in one day or over a couple of days. It is interesting to note that the user cost factor is ranked lowly by both DMs as well as PMs, even though this factor is related to congestion.

Due to the characteristics of DM operations, maintenance cost is highly ranked compared to the results for PMs. In addition, availability of material and equipment repair is higher since many projects can be finished within a day if there are no problems with availability of material or no breakdown of equipment. 


\section{Contractors' Results}

Table 5 shows the contractors' results and there are obvious differences as compared to other results. The traffic control and congestion factors are ranked relatively low among contractors, but productivity, construction cost, and quality factors are highly ranked. Even though lighting is ranked third in the indicating factors, it is not consistent with its ranking in ranking factors because it is ranked $10^{\text {th }}$. For contractors, productivity and construction costs are very important factors because these factors are directly related to profits. Thus, factors such as public relations, user cost, noise, maintenance cost, air quality, and fuel consumption that are not related to its profits ranked lower in importance.

\section{Other DOTs' Results}

Table 6 shows other state DOTs' results and typical positions of respondents were director, engineer, or researcher. The public relations and user cost factors are relatively higher in this category, which is a reasonable result as one would expect these to be ranked highly since congestion and traffic control are in the top 3 most important factors and these factors are related to public relations and user cost. However, the quality factor is ranked $14^{\text {th }}$ in indicating whereas it is rated $5^{\text {th }}$ in ranking. This makes it difficult to conclude whether other states consider the quality factor to be very important or not. Since participating personnel are in a higher positions in other states, they may not directly participate in construction or maintenance projects at workplaces. Thus, communication supervision and availability of material/equipment repair factors are ranked lower. In addition, construction cost and maintenance cost are ranked lower. This study raises the question of whether DOTs do not consider construction and maintenance costs to be critical as long as the public and workers are satisfied about safety and congestion issues.

\section{Analysis of Comparisons}

It is necessary to compare the overall result to each individual category to check for internal consistency. In addition, the results of PMs and DMs surveys need more in depth analysis since the sample size is large, it consists of different regions and positions, and its operations vary (construction versus maintenance work).

\section{Comparison between PMs and DMs}

In order to compare regions and positions in personnel categories (e.g., PMs, DMs), an ANOVA test was used, and $\mathrm{p}$ values of less than .05 were considered to be significant. A hypothesis test was used to investigate whether there are any differences between PMs' and DMs' responses. Table 7 shows the results. Six factors in indicating and the five factors in ranking are different. In particular, the maintenance cost and availability of material/equipment repair factors significantly differ in both indicating and ranking factors. This means that DMs weigh these two factors more heavily and this fact is a representative characteristic of the DM category. The construction cost and noise factors are higher in ranking by PMs, but there in no difference in ranking. Since the length of projects for PMs is generally longer than for DMs, PM personnel consider these two factors more seriously. However, even though other factors are different in either indicating or ranking, the factors' ranked positions are similar, so these differences can be minimized.

\section{Preference of Work Time and Other Information}

The study asked participants for their preference between daytime and nighttime work. $83 \%$ of participants prefer daytime work, $7 \%$ of participants prefer nighttime work, and $10 \%$ of participants do not have a preference. This overall result is very similar to that of the various personnel categories. From the text responses, the main reason why people prefer daytime work is personal schedules and safety. If workers have to work at nighttime, they cannot have time with their family or friends at night. Even though some participants agreed that working at nighttime was better for productivity, congestion, and safety, they just did not want to ruin their personal lives. Many participants felt that working at night is more dangerous than working during the day and some participants shared their accident experiences due to working at nighttime. In addition, participants wrote that sleeping in the daytime instead of at nighttime is not good for biological rhythms, so they argued that humans should sleep at night and do activities in the daytime.

The participants who preferred to work at nighttime said that working at night is better because the reduced traffic during the nighttime enables workers to be more productive work in a safer environment. It can be concluded that many workers think that working at nighttime is not bad based on their experiences, but it is not preferable because of the effect on personal lives. To the question that asked if there was anything else they would like to share, participants typically provided more and more detailed information concerning why working at daytime or nighttime is better. 
When investigators surveyed contractors and other states' DOTs, the survey asked additionally whether they do nighttime work. All participants responded that the company conducts nighttime work if the company needs to do so. Also, of all the states that responded to the survey, only Montana did not perform nighttime work. The representative of Montana said that they do not need to conduct nighttime work due to low traffic volume in the daytime.

\section{CONCLUSION}

Through the survey, the importance of factors affecting nighttime work were analyzed from various perspectives. The overall result has been summarized and comparisons between each individual personnel categories were made to investigate whether the overall result is consistent with them. Based on this analysis, the overall result is fairly consistent with the results from the individual respondent groups with the exception of the cost factors such as construction, maintenance, and user cost. Even though noise, communication supervision, and availability of material/equipment repair factors are slightly different, these factors are not likely to significantly influence decision-making on when to conduct nighttime work.

While the literature suggests that nighttime work produces good productivity and quality, and often provides safer working environments, these survey results indicate that most people do not want to work at night because of the disruption to their private lives. Using the results of this survey and the recommendations of the TAC, the factors can be weighted and a decision model developed to determine when nighttime work should be conducted.

This study has successfully characterized the importance of factors related to daytime versus nighttime decision-making. The results provide the ability to determine weights and to build a decision model to improve the effectiveness of decision-making. Oregon is currently developing their decision model using the overall results from this survey. The authors recommend that if other states elect to incorporate these results into a decision model that the importance values from the "Other DOT's" be used rather than the overall results.

\section{ACKNOWLEDGEMENTS}

The authors would like to thank the Technical Advisory Committee (see list below) for their input regarding this project:

Scott McCana, ODOT Roadway Engineering

Ken Stoneman, ODOT Region 1

Sam Johnston, Traffic Management Section

James Jackson, Wildish Standard Paving Co.

Mike Anderson, Morse Brothers

Jeff Graham, FHWA

Doug Hedlund, ODOT Office of Maintenance

Tom Lauer, ODOT Region 2

Jim Huddleston, APAO

\section{REFERENCES}

1. Sherpard, F. D., \& Cottrell, B. H., Jr. (1985, December). Benefits and safety impact of night work zone activities. Virginia Highway and Transportation Research Council.

2. Price, D. A. (1985). Nighttime paving (Report No. CDOH-DTP-R-85-2). Colorado Department of Highways.

3. Hinze, J. W., \& Carlisle, D. (1990a). An evaluation of the important variables in nighttime construction. Transportation Northwest (TransNow), University of Washington, Department of Civil Engineering.

4. Hinze, J. W., \& Carlisle, D. L. (1990b) Variables affected by nighttime construction projects (Transportation Research Record 1282).

5. $\quad$ Ellis, R. D., Herbsman, Z. J., Kumar, A., \& Chheda, P. N. (1991, December). Developing night operations in Florida (Final Report FL/DOT/RMC/0548/3543). Gainesville: University of Florida, Department of Civil Engineering. 
6. Ellis, R. D., Herbsman, Z. J., Chheda, P. N., Epstein, W. C., \& Kumar, A. (1993, January). Developing procedures for night operations (Final Report UTC-UF-326-93-1). Gainesville: University of Florida, Transportation Research Center.

7. Ellis, R. D., Herbsman, Z., \& Kumar, A. (1993, December). Development of work zone lighting standards for FDOT nightwork projects (Final Report FL/DOT/ ). Gainesville: University of Florida, Department of Civil Engineering.

8. Elrahman, O. A. \& Perry, R. J. (1994). Night-Time Construction Operations (Report FHWA/NY/SR94/116). Engineering Research and Development Bureau, New York State Department of Transportation.

9. Elrahman, O. A. \& Perry, R. J. (1998, March). When it pays to work at night. Public Works, 60-66.

10. Ellis, R. D. \& Kumar, A. (1993). Influence of nighttime operations on construction cost and productivity. Transportation Research Record (No. 1389). 


\section{LIST OF TABLES AND FIGURES}

FIGURE 1 Surveyed Personnel

FIGURE 2 Responses by Respondent Type

TABLE 1 Responses from Other States

TABLE 2 Overall Result

TABLE 3 Project Managers' Offices Result

TABLE 4 District Managers' Offices Result

TABLE 5 Contractors' Result

TABLE 6 Other States' Result

TABLE 7 ANOVA and Hypothesis Tests for Regions and Positions by Categories 


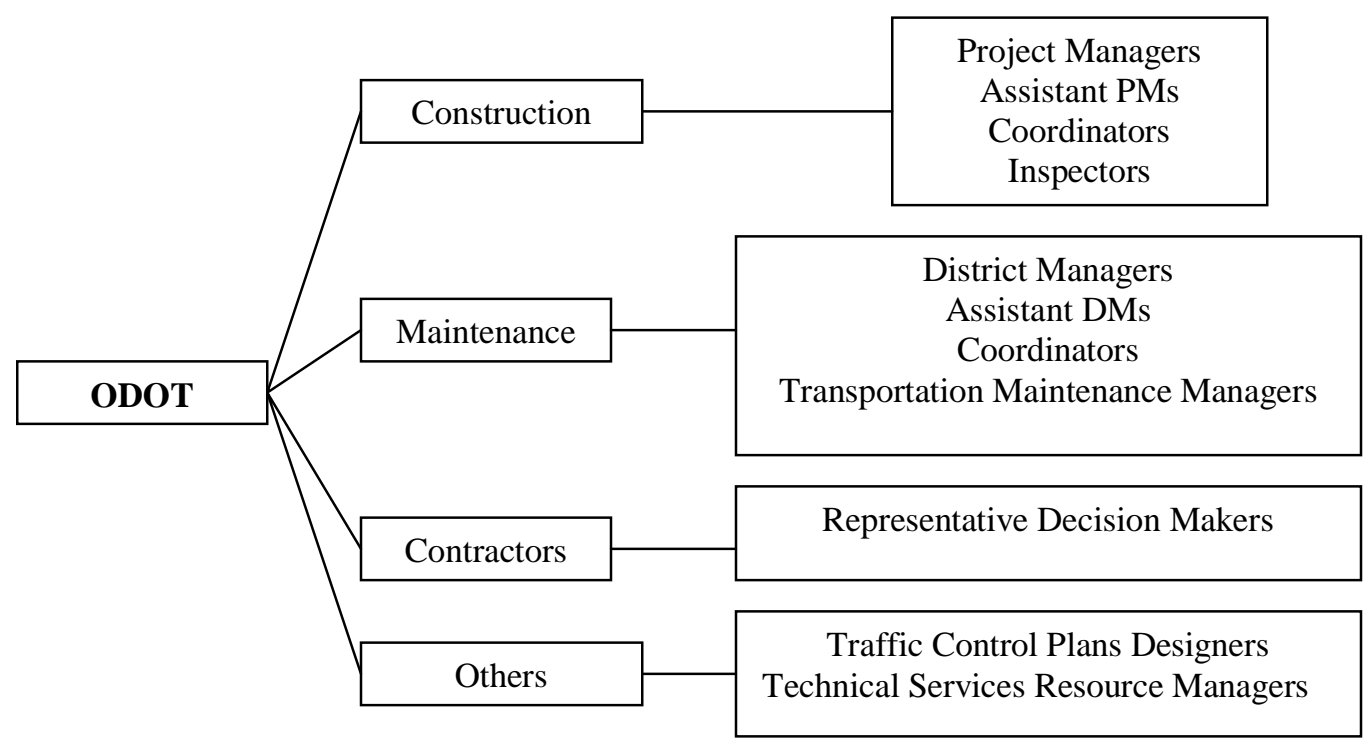

Other DOTs

Representative Decision Makers

FIGURE 1 Surveyed Personnel 


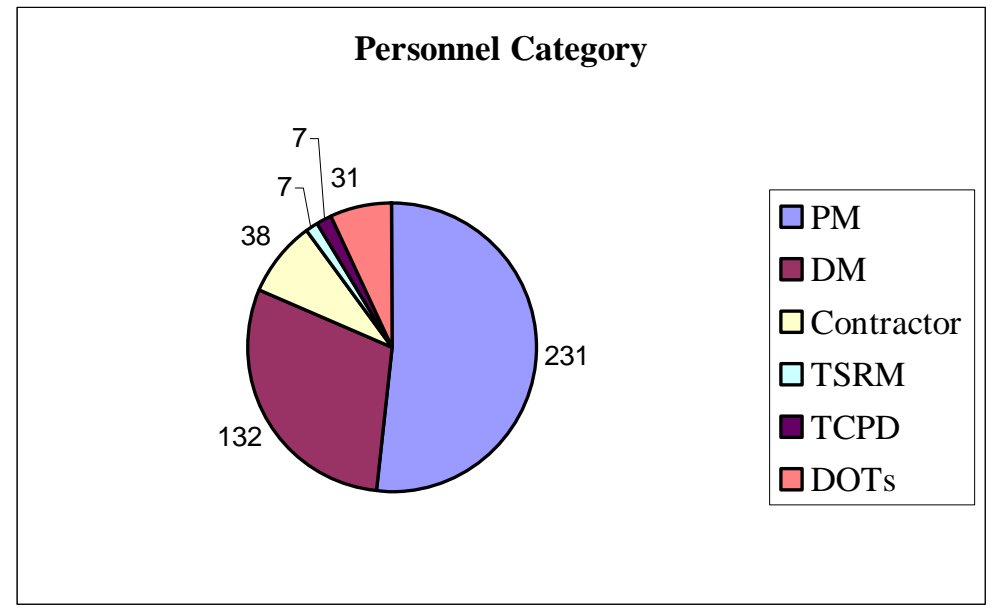

FIGURE 2 Responses by Respondent Type 
TABLE 1 Responses from Other States

\begin{tabular}{|c|c|c|}
\hline Response States & Number of Response & Not Response States \\
\hline Arizona & 1 & Alabama \\
Colorado & 1 & Alaska \\
Connecticut & 1 & Arkansas \\
Delaware & 1 & California \\
Florida & 1 & Hawaii \\
Georgia & 1 & Idaho \\
Illinois & 1 & Kansas \\
Indiana & 2 & Maine \\
Iowa & 1 & Maryland \\
Kentucky & 1 & Massachusetts \\
Louisiana & 4 & Minnesota \\
Michigan & 1 & Mississippi \\
Montana & 1 & Missouri \\
Nebraska & 1 & New Hampshire \\
Nevada & 1 & New Mexico \\
New Jersey & 1 & North Carolina \\
New York & 2 & North Dakota \\
Oklahoma & 1 & Ohio \\
Pennsylvania & 1 & Rhode Island \\
Tennessee & 1 & South Carolina \\
Utah & 1 & South Dakota \\
Virginia & 2 & Texas \\
Washington & 1 & Vermont \\
Wisconsin & 1 & Wotal 25 States \\
Wyoming & 1 & West Virginia \\
& & \\
\hline Total 25 States & & \\
& & \\
\hline
\end{tabular}




\section{TABLE 2 Overall Result}

\begin{tabular}{|c|c|c|c|}
\hline \multicolumn{4}{|c|}{ Overall $(\mathbf{n = 4 4 6 )}$} \\
\hline Indicating & Rverage & Factor & Average \\
\hline Factor & 6.44 & Safety & 2.08 \\
\hline Safety & 6.07 & Traffic Control & 4.05 \\
\hline Traffic Control & 5.98 & Congestion & 4.83 \\
\hline Congestion & 5.84 & Quality & 6.64 \\
\hline Lighting & 5.40 & Productivity & 7.32 \\
\hline Quality & 5.32 & Worker Condition & 7.90 \\
\hline Public Relations & 5.19 & Driver Condition & 8.76 \\
\hline Worker Condition & 5.11 & Lighting & 9.12 \\
\hline Productivity & 5.07 & Public Relations & 9.42 \\
\hline Scheduling & 5.04 & Construction Cost & 10.16 \\
\hline Driver Condition & 4.94 & Scheduling & 10.23 \\
\hline Construction Cost & 4.92 & Accident Cost & 11.13 \\
\hline Accident Cost & 4.70 & Noise & 11.74 \\
\hline Availability of Mat'/Equip' Repair & 4.64 & User Cost & 11.91 \\
\hline Communication Supervision & 4.57 & Maintenance Cost & 12.16 \\
\hline Noise & 4.52 & Availability of Mat'/Equip' Repair & 12.20 \\
\hline User Cost & 4.46 & Communication Supervision & 12.61 \\
\hline Maintenance Cost & 3.27 & Air Quality & 15.24 \\
\hline Air Quality & 2.89 & Fuel Consumption & 16.43 \\
\hline Fuel Consumption & & & \\
\hline
\end{tabular}


TABLE 3 Project Managers' Offices Result

\begin{tabular}{|c|c|c|c|}
\hline \multicolumn{4}{|c|}{ PM $(\mathbf{n = 2 3 1})$} \\
\hline \multicolumn{2}{|c|}{ Indicating } & \multicolumn{2}{c|}{ Ranking } \\
\hline Factor & Average & Factor & Average \\
\hline Safety & 6.55 & Safety & 1.90 \\
\hline Traffic Control & 6.13 & Traffic Control & 3.94 \\
\hline Congestion & 5.89 & Congestion & 5.06 \\
\hline Lighting & 5.89 & Quality & 6.18 \\
\hline Quality & 5.47 & Productivity & 7.54 \\
\hline Public Relations & 5.26 & Worker Condition & 7.61 \\
\hline Worker Condition & 5.15 & Driver Condition & 8.05 \\
\hline Productivity & 5.04 & Lighting & 8.93 \\
\hline Driver Condition & 5.02 & Public Relations & 9.62 \\
\hline Scheduling & 4.89 & Construction Cost & 9.74 \\
\hline Accident Cost & 4.86 & Scheduling & 10.53 \\
\hline Construction Cost & 4.81 & Noise & 11.23 \\
\hline Noise & 4.70 & Accident Cost & 11.44 \\
\hline Communication Supervision & 4.51 & User Cost & 12.21 \\
\hline User Cost & 4.37 & Communication Supervision & 12.34 \\
\hline Availability of Mat'/Equip' Repair & 4.25 & Maintenance Cost & 13.39 \\
\hline Maintenance Cost & 4.17 & Availability of Mat'/Equip' Repair & 13.54 \\
\hline Air Quality & 3.53 & Air Quality & 14.89 \\
\hline Fuel Consumption & 3.02 & Fuel Consumption & 16.12 \\
\hline
\end{tabular}




\section{TABLE 4 District Managers' Offices Result}

\begin{tabular}{|c|c|c|c|}
\hline \multicolumn{4}{|c|}{ DM $\quad(n=132)$} \\
\hline \multicolumn{2}{|l|}{ Indicating } & \multicolumn{2}{|l|}{ Ranking } \\
\hline Factor & Average & Factor & Average \\
\hline Safety & 6.41 & Safety & 1.89 \\
\hline Traffic Control & 6.21 & Traffic Control & 3.68 \\
\hline Congestion & 6.10 & Congestion & 4.80 \\
\hline Lighting & 5.99 & Productivity & 7.48 \\
\hline Public Relations & 5.60 & Quality & 7.61 \\
\hline Quality & 5.48 & Worker Condition & 7.67 \\
\hline Availability of Mat'/Equip' Repair & 5.44 & Lighting & 8.91 \\
\hline Maintenance Cost & 5.34 & Driver Condition & 9.06 \\
\hline Worker Condition & 5.31 & Public Relations & 9.32 \\
\hline Scheduling & 5.27 & Maintenance Cost & 9.45 \\
\hline Driver Condition & 5.24 & Availability of Mat'/Equip' Repair & 9.92 \\
\hline Accident Cost & 5.14 & Scheduling & 10.03 \\
\hline Productivity & 5.13 & Accident Cost & 11.28 \\
\hline Construction Cost & 5.03 & Construction Cost & 11.61 \\
\hline Communication Supervision & 4.85 & User Cost & 12.41 \\
\hline User Cost & 4.69 & Communication Supervision & 12.73 \\
\hline Noise & 4.42 & Noise & 13.22 \\
\hline Air Quality & 3.06 & Air Quality & 15.66 \\
\hline Fuel Consumption & 2.91 & Fuel Consumption & 16.93 \\
\hline
\end{tabular}


TABLE 5 Contractors' Result

\begin{tabular}{|c|c|c|c|}
\hline \multicolumn{4}{|c|}{ Contractors $(\mathrm{n}=\mathbf{3 8})$} \\
\hline \multicolumn{2}{|l|}{ Indicating } & \multicolumn{2}{|l|}{ Ranking } \\
\hline Factor & Average & Factor & Average \\
\hline Safety & 6.29 & Safety & 3.00 \\
\hline Productivity & 6.03 & Productivity & 4.52 \\
\hline Lighting & 5.84 & Traffic Control & 5.36 \\
\hline Traffic Control & 5.68 & Quality & 5.91 \\
\hline Construction Cost & 5.68 & Congestion & 6.06 \\
\hline Quality & 5.66 & Construction Cost & 7.33 \\
\hline Congestion & 5.63 & Worker Condition & 7.69 \\
\hline Availability of Mat'/Equip' Repair & 5.58 & Accident Cost & 9.59 \\
\hline Worker Condition & 5.50 & Driver Condition & 9.75 \\
\hline Scheduling & 5.34 & Lighting & 9.79 \\
\hline Communication Supervision & 5.06 & Scheduling & 10.21 \\
\hline Driver Condition & 4.97 & Availability of Mat'/Equip' Repair & 10.24 \\
\hline Accident Cost & 4.94 & Communication Supervision & 11.45 \\
\hline Public Relations & 4.34 & Public Relations & 11.64 \\
\hline User Cost & 3.97 & User Cost & 12.21 \\
\hline Noise & 3.84 & Maintenance Cost & 12.56 \\
\hline Maintenance Cost & 3.69 & Noise & 12.61 \\
\hline Air Quality & 2.42 & Air Quality & 14.91 \\
\hline Fuel Consumption & 2.28 & Fuel Consumption & 16.31 \\
\hline
\end{tabular}




\section{TABLE 6 Other States' Result}

\begin{tabular}{|c|c|c|c|}
\hline \multicolumn{4}{|c|}{ DOTs $(\mathbf{n = 3 1})$} \\
\hline Indicating & \multicolumn{2}{|c|}{ Ranking } \\
\hline Factor & Average & Factor & Average \\
\hline Congestion & 6.57 & Safety & 2.41 \\
\hline Safety & 6.07 & Congestion & 2.93 \\
\hline Traffic Control & 6.03 & Traffic Control & 4.66 \\
\hline Public Relations & 5.93 & Public Relations & 6.03 \\
\hline User Cost & 5.53 & Quality & 6.61 \\
\hline Scheduling & 5.30 & User Cost & 7.38 \\
\hline Lighting & 5.10 & Productivity & 7.66 \\
\hline Noise & 4.73 & Scheduling & 8.83 \\
\hline Worker Condition & 4.65 & Noise & 9.45 \\
\hline Productivity & 4.53 & Accident Cost & 10.29 \\
\hline Driver Condition & 4.48 & Lighting & 10.45 \\
\hline Accident Cost & 4.48 & Worker Condition & 10.50 \\
\hline Communication Supervision & 4.40 & Driver Condition & 11.21 \\
\hline Quality & 4.38 & Construction Cost & 11.25 \\
\hline Construction Cost & 4.24 & Availability of Mat'/Equip' Repair & 12.93 \\
\hline Availability of Mat'/ Equip' Repair & 4.24 & Maintenance Cost & 13.43 \\
\hline Maintenance Cost & 3.74 & Communication Supervision & 14.36 \\
\hline Air Quality & 3.46 & Air Quality & 16.29 \\
\hline Fuel Consumption & 2.68 & Fuel Consumption & 17.00 \\
\hline
\end{tabular}


TABLE 7 ANOVA and Hypothesis Tests for Regions and Positions by Categories

\begin{tabular}{|l|c|c|c|c|c|c|c|c|}
\hline \multirow{2}{*}{} & \multicolumn{9}{|c|}{ p- value } & \multicolumn{3}{c|}{ DM } & \multicolumn{2}{c|}{ PMpothesis Test } \\
\cline { 2 - 9 } & \multicolumn{4}{|c|}{ PM DM } \\
\cline { 2 - 9 } & IR & IP & RR & RP & IR & RR & I & R \\
\hline Congestion & 0.22 & 0.51 & 0.95 & 0.08 & 0.31 & 0.92 & NE & E \\
Safety & 0.51 & 0.77 & 0.63 & 0.25 & 0.00 & 0.00 & E & E \\
Traffic Control & 0.84 & 0.26 & 0.69 & 0.09 & 0.08 & 0.10 & E & E \\
Productivity & 0.73 & 0.14 & 0.76 & 0.42 & 0.28 & 0.17 & E & E \\
Quality & 0.82 & 0.67 & 0.83 & 0.60 & 0.02 & 0.15 & E & NE \\
Driver Condition & 0.87 & 1.00 & 0.70 & 0.56 & 0.53 & 0.45 & E & E \\
Worker Condition & 0.18 & 0.81 & 0.16 & 0.53 & 0.00 & 0.20 & E & E \\
User Cost & 0.54 & 0.10 & 0.70 & 0.01 & 0.26 & 0.69 & E & E \\
Accident Cost & 0.29 & 0.42 & 0.52 & 0.25 & 0.07 & 0.12 & NE & E \\
Maintenance Cost & 0.41 & 0.34 & 0.84 & 0.91 & 0.18 & 0.11 & NE & NE \\
Construction Cost & 0.74 & 0.02 & 0.64 & 0.67 & 0.22 & 0.47 & E & NE \\
Noise & 0.04 & 0.03 & 0.00 & 0.04 & 0.33 & 0.35 & E & NE \\
Fuel Consumption & 0.32 & 0.00 & 0.38 & 0.71 & 0.04 & 0.53 & E & E \\
Air Quality & 0.86 & 0.00 & 0.33 & 0.22 & 0.06 & 0.42 & E & E \\
Scheduling & 0.39 & 0.48 & 0.70 & 0.22 & 0.93 & 0.21 & NE & E \\
Public Relations & 0.04 & 0.11 & 0.44 & 0.09 & 0.34 & 0.18 & NE & E \\
Communication Supervision & 0.89 & 0.08 & 0.11 & 0.04 & 0.36 & 0.03 & E & E \\
Availability of Mat'/Equip' Repair & 0.94 & 0.00 & 0.23 & 0.00 & 0.03 & 0.29 & NE & NE \\
Lighting & 0.69 & 0.06 & 0.19 & 0.06 & 0.10 & 0.00 & E & E \\
\hline
\end{tabular}

\footnotetext{
<Note $\quad$ IR: Indicating by Regions

IP: Indicating by Positions

RR: Ranking by Regions

RP: Ranking by Positions

I: Indicating

R: Ranking

NE: Not Equal; Reject Hypothesis

E: Equal; Do not Reject Hypothesis
} 